\title{
Measuring The Thickness of Native Plutonium Oxides Using EPMA
}

\author{
Troy Nothwang, Charles C. Davis, and Rollin E. Lakis
}

\section{Los Alamos National Laboratory, P.O. Box 1663, Los Alamos NM87545.}

Plutonium $(\mathrm{Pu})$ is a very reactive metal that rapidly forms a thick, moderately protective surface dioxide $\left(\mathrm{PuO}_{2}\right)$. In dry air the corrosion rate is slow, approximately $200 \mathrm{~nm}$ per year [1]. But in moist air, the oxidation rate at room temperature increases by 200 times. At $100{ }^{\circ} \mathrm{C}$ in moist air, the rate is 100,000 times that of dry air. The clean metallic surface develops characteristic interference colors that are a result of the optical properties of the growing oxide and its increasing thickness. In ambient air conditions the oxidation of pure, alpha-phase Pu metal, can be observed in real-time by watching the change in color. An alloy addition of about $1 \%$ wt Gallium (Ga) stabilizes the $\mathrm{Pu}$ delta-phase (FCC phase stable above $300^{\circ} \mathrm{C}$ ) and reduces the rate of oxidation. Previously, ellipsometry was used to correlate the thickness of the surface oxide layer with color [2]. In deltastabilized $\mathrm{Pu}$ the color changes from gold to violet and then blue in the thickness range of $40 \mathrm{~nm}$ to $80 \mathrm{~nm}$. This color scale is often used as a quick method to very roughly determine the thickness of surface oxide on Pu metal, but it is very qualitative in nature and the effect of subtle changes in the oxide composition or metallic surface preparations might significantly affect a thickness estimate. In this work we attempt to measure the thickness of ambient grown Pu oxides using EPMA data and STRATAGem 3.0 Thickness and Composition Thin Film Analysis software package.

Six Pu-Ga alloy standards with a Ga concentration range of $0.5-2.0 \mathrm{wt} \%$ were prepared by arcmelting and annealed for $200 \mathrm{hrs}$. at $420{ }^{\circ} \mathrm{C}$. These materials have been extensively evaluated for heterogeneity using EPMA, and they have been successfully utilized as microanalysis standards. The standards were permitted to age in the ambient environment for a period of several months. EPMA measurements of oxygen k-ratios relative to a $\mathrm{PuO}_{2}$ standard were made at accelerating voltages of 5, 10, 15, 18 and $20 \mathrm{kV}$ using a JEOL JSM-8200. Oxygen K $\alpha$ characteristic x-rays were analyzed using synthetic multilayer crystal with $6 \mathrm{~nm}$ lattice spacing. The STRATAGem thin film calculation assumed that all of the measured oxygen was present on the surface in the form of a $\mathrm{PuO}_{2}$ thin film, and then calculated the apparent thickness of the oxide layer.

Figure 1. is a plot of measured oxygen k-ratios as a function of accelerating voltage for the $0.7 \mathrm{wt} \%$ $\mathrm{Ga}$ alloy and a series of lines-of-constant-oxide-thickness calculated using Stratagem. The data trend qualitatively with the simulations and the apparent precision of the oxide thickness is quite good, on the order of $+/-$ a few nanometers. The accuracy of the measurement is unknown at this time because there is no independent measure of oxide thickness other than color. Table 1 contains a summary of the measured oxide thickness for all the specimens.

[1] Los Alamos Science, number 26, 2000, P16-27.

[2] D. T. Larson, D. L. Cash, Plutonium Oxide Thickness - Color Correlation, CPRD940338-114, The Dow Chemical Company, Rocky Flats Division. 


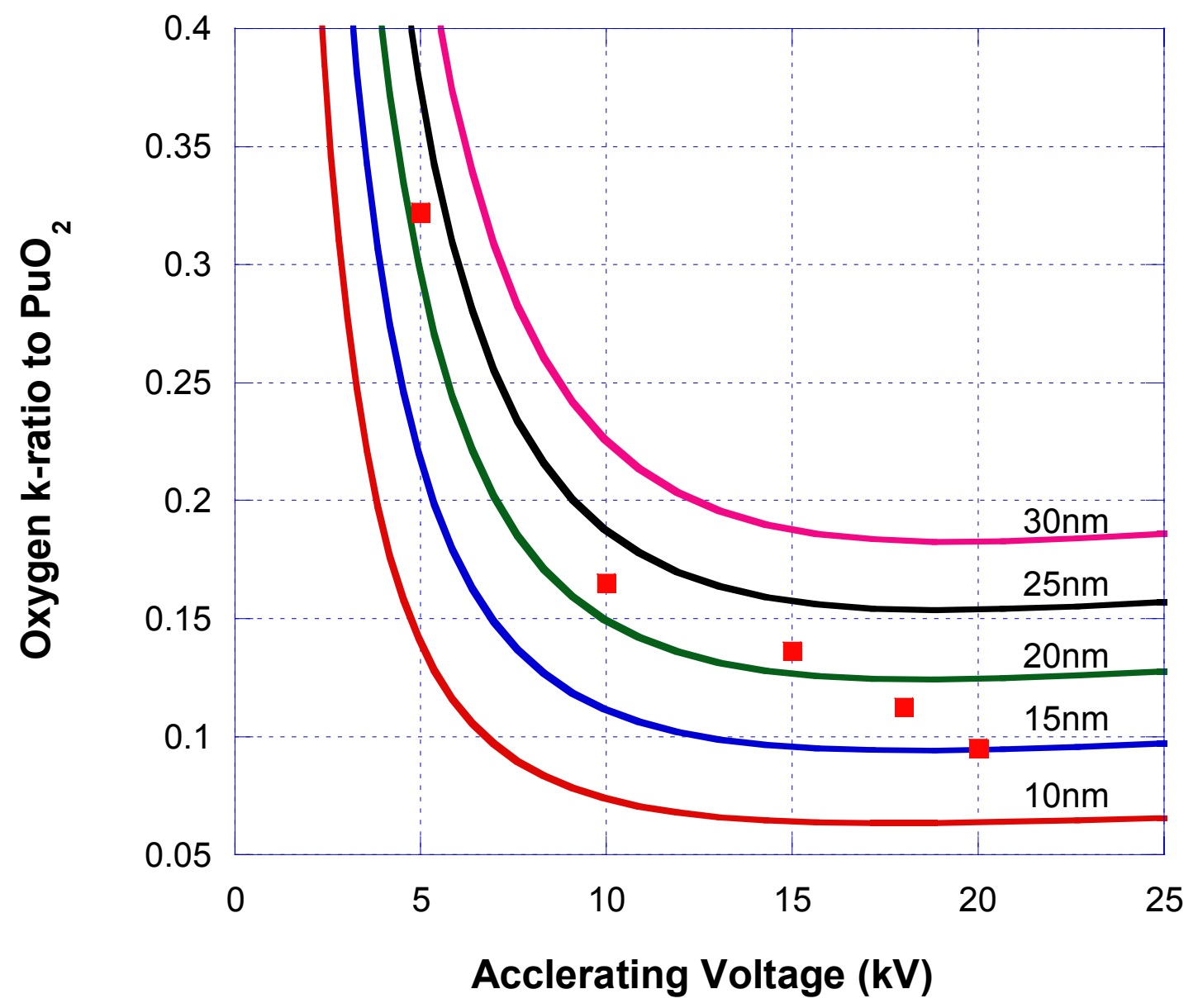

Figure 1. Plot of measured oxygen k-ratios as a function of accelerating voltage for the $0.7 \mathrm{wt} \% \mathrm{Ga}$ alloy and a series of lines-of-constant-oxide-thickness calculated using STRATAGem.

\begin{tabular}{|c|c|}
\hline \multicolumn{2}{|c|}{ Table 1. Calculated $\mathbf{P u O}_{\mathbf{2}}$ Layer Thickness } \\
\hline $\begin{array}{c}\text { Alloy Composition } \\
\text { Ga wt\% }\end{array}$ & $\begin{array}{c}\text { Layer Thickness } \\
\text { (nm) }\end{array}$ \\
\hline 0.5 & 23.5 \\
\hline 0.7 & 21.9 \\
\hline 0.9 & 25.3 \\
\hline 1.1 & 28.8 \\
\hline 1.4 & 29.9 \\
\hline 2.0 & 31.8 \\
\hline
\end{tabular}

